\title{
Announcement
}

\section{Essen Symposium 1986}

The ninth International Essen Symposium will take place 8-11 September 1986, at the Universitätsbibliothek Essen, FRG, under the theme "Impact of new information technology on international library cooperation". It will offer an excellent opportunity for those who are dealing with library automation to present new developments in this area, and to discuss the related problems. The language of the Symposium will be English. Topics to be discussed will include:

- latest developments in telecommunications

- optical disk technology and libraries

- computer communications protocols ( $\mathrm{CCP}$ ), open systems interconnection (OSI), standard network interconnection (SNI)

- common command language (CCL), and artificial intelligence (AI) for accessing data bases

- multi-microprocessors and their role in local-area networks, distributed systems, and networks

- impact of linked systems in national and international library networking

- future of a European library information network.

As in 1985, the commercial market will be well represented. An exhibition of systems providing online demonstration of computerized bibliographic data bases and information retrieval systems will be open throughout the Symposium, and 'vendor sessions' will be incorporated into the programme to enable suppliers to address Symposium attendees.

No attendance fee is charged. Participants are responsible for their own travel and accommodation costs. Commercial institutions are kindly requested to pay all costs needed for their online presentations. In addition, a sum of $\$ 500$ will be raised to arrange a reception on behalf of the participating commercial institutions.

Those interested in applying for participation may do so by sending their names, affiliations, and contact information (postal address, telephone and telex numbers) to the following address, from which further information is also available:

Essen Symposium 1986

Gesamthochschulbibliothek Essen

Postfach 101454, Universitätsstr. 9

4300 Essen 1, FRG

tel. (0201) 183 3700; telex 857239 ueghbd 